\title{
Epidemiology of hepatitis B infection in the Western Pacific and South East Asia
}

\author{
I D Gust
}

\begin{abstract}
The Western Pacific and South East Asia regions are the largest and most populous of the six World Health Organisation regions and include more than 40 countries. More than $75 \%$ of the world's estimated 350 million carriers are located here. The region has therefore provided many insights into the epidemiology, natural history, and control of hepatitis $B$ infection and has been home to the first national control programmes. Hepatitis B is hyperendemic in most countries of the region, with carrier rates ranging from 5-35\% except in Australia, New Zealand, and Japan, where the mean carrier rate is less than $2 \%$. Patterns of infection vary considerably from country to country, city to city, and even village to village, and can change with time. Most infections are acquired early in childhood or in early adult life. A variety of control measures are in place and many countries in the region have introduced widespread or universal childhood immunisation policies with significant success. While it is theoretically possible that hepatitis $B$ infection could be eradicated by universal childhood immunisation, there are several biological and practical issues that make this extremely difficult, suggesting that, for the foreseeable future, control may be a more realisable goal.

(Gut 1996; 38 (suppl 2): S18-S23)
\end{abstract}

Keywords: hepatitis B, epidemiology, Western Pacific, South East Asia, immunisation.

\section{Introduction}

The World Health Organisation (WHO) allocates its member states to one of six regions, largely, but not exclusively, on a geographical basis. The Western Pacific and South East Asia regions are the largest and most populous regions, including more than 40 countries, ranging in size from China - with its population of more than one billion - to the tiny Pacific islands of Nauru and Niue, whose combined populations are less than 20000 . The region contains prosperous, highly developed countries such as Japan, Australia, and New Zealand, countries that are rapidly industrialising, such as Singapore, Malaysia, Indonesia, and the Republic of Korea, and countries such as the Philippines and Myanmar, which are less prosperous. A variety of health systems are in place, with per capita expenditure varying from a few dollars per annum in some of the smaller island states, to about $\$ 2000$ per annum in Japan and Australia.

The region has had an important impact on our understanding of hepatitis B infection and was the first to accept its public health significance by introducing national control programmes. The high prevalence of infection and the existence of many excellent clinical and laboratory facilities have led to the region becoming the site of many of the pivotal studies in this field. The hepatitis B surface antigen (HBsAg) was originally detected in sera collected from Australian aborigines ${ }^{1}$ and the importance of perinatal transmission from carrier mothers was established by the pioneering studies of Palmer Beasley and his colleagues in Taiwan. ${ }^{2}$ Beasley et al also demonstrated that perinatal transmission could be interrupted by the use of hyperimmune globulin or immunisation with hepatitis $B$ vaccine, or both. ${ }^{3}$ These workers and colleagues in China and Japan subsequently demonstrated that chronic infection with $\mathrm{HBV}$ was associated with a significantly increased risk of chronic liver disease. ${ }^{4-6} \mathrm{Nauru}^{7}$ was the first country to introduce universal childhood immunisation programmes in an attempt to reduce the burden of chronic liver disease, while China and the Republic of Korea were the first countries in the developing world to attempt to control hepatitis B by widespread immunisation, using locally produced vaccine.

The main features of the epidemiology of hepatitis B in South East Asia and the Western Pacific have been reported elsewhere. ${ }^{8-16}$ Briefly, hepatitis B infection is hyperendemic; with the exception of Australia, New Zealand, and Japan, where the mean carrier rate is less than $2 \%$, carrier rates range between 5 and $35 \%$, with most in the 5 to $15 \%$ range (Table I).

Because the region is so densely populated and carrier rates are relatively high, it contains

TABLE I Prevalence of $\mathrm{HBs}$ Ag in healthy adults (adapted from Sung et $\mathrm{al}^{9}$ )

\begin{tabular}{lc}
\hline Population & Percentage \\
\hline Chinese & \\
Taiwan & 15 \\
Southern China & 12 \\
Singapore & 14 \\
Hong Kong & 10 \\
Aboriginal (Australia) & $5-25$ \\
Mediterranean (Australia) & $2-5$ \\
Maori (New Zealand) & $10-12$ \\
Korean & 12 \\
Burmese & $8-10$ \\
Indonesian & 5 \\
Indian & $5-15$ \\
Japanese & $1-3$ \\
Anglo-Saxon & \\
Australia & $0 \cdot 1$ \\
New Zealand & $0 \cdot 1$ \\
\hline
\end{tabular}

Note: most figures are rounded to the nearest whole number.
CSL Limited, Parkville, Victoria Australia

Correspondence to: Dr I D Gust, CSL Limited, 45 Poplar Road, Parkville, Melbourne, Victoria 3052, Australia. 
TABLE II Prevalence of HBeAg in adult carriers of $H B s A g$

\begin{tabular}{lll}
\hline & Percentage & Reference \\
\hline China (Hebei province) & 30 & 29 \\
Indonesia (Java) & 21 & 12 \\
Taiwan & 40 & 30 \\
Japan & 25 & 23 \\
Nauru & 10 & 21 \\
Australia & & \\
$\quad$ European origin & 8 & 31 \\
$\quad$ Chinese origin & 37 & 31 \\
\hline
\end{tabular}

more than three quarters of the estimated 350 million carriers in the world. As many of these infections are acquired early in life and life expectancy is increasing in most countries, serious sequelae of chronic infection (chronic active hepatitis, cirrhosis and primary hepatocellular carcinoma) are increasingly common. A high proportion of the one to two million deaths, which are calculated to occur each year from these conditions, occur in South East Asia and the Western Pacific Region.

While broad details of the epidemiological picture can be defined, it is important to note that major differences in the pattern of infection occur within countries, towns, villages, and families. Among the most striking are the different infection rates and carrier rates among ethnic groups living alongside one another. This was first shown in Fiji where the carrier rate is considerably higher in the indigenous Melanesian population than in the equally numerous Indian population. ${ }^{17}$ Similar differences exist between the Maori and nonMaori populations in New Zealand ${ }^{18}$ and the aboriginal and non-aboriginal populations in Australia. ${ }^{19}$ In Australia, carrier rates reflect those found in the countries in which the individual's parents or grandparents were born, being lowest (about $0.1 \%$ ) in descendants of British migrants, higher (2-5\%) among migrants and the children of migrants from the Mediterranean region, and highest (5-15\%) among migrants from the Pacific islands and South East Asia. ${ }^{20}$

Even in isolated populations with high infection rates, pronounced differences exist at the village or hamlet level. In Nauru, which has a population of less than 7000 people who live in a series of villages around a narrow coastal strip, the carrier rates in communities with similar infection rates vary from $5 \cdot 6 \%$ to $29 \cdot 4 \% .^{21}$

The epidemiology of hepatitis $B$ infection in a community can change significantly over a comparatively brief period, through public health interventions, changes in the pattern of intravenous drug use, or mass movements of people through migration. A considerable proportion of Australia's estimated 250000 carriers of $\mathrm{HBV}$ have entered the country recently, as refugees from Vietnam and Cambodia, while the prevalence of hepatitis B infection among children in Taiwan, ${ }^{22}$ Japan, ${ }^{23}$ New Zealand, ${ }^{24}$ Nauru, ${ }^{25}$ and Singapore, ${ }^{26}$ has declined dramatically, due to widespread immunisation campaigns.

\section{Routes of transmission}

Much of the information on transmission of HBV in South East Asia and the Western
Pacific Region is speculative and based on inferences from cross sectional epidemiological studies. In hyperendemic countries, the age specific prevalence of markers of infection increases steadily with increasing age, although some decline in the carrier rate and the prevalence of antibody is often seen in the last two decades of life. The decline in the carrier rate with increasing age is more pronounced in women than men. ${ }^{27} 28$ In these countries, most infections seem to occur: (a) either at, or shortly after, birth, when newborn babies are exposed to the infected blood or bloodstained secretions of carrier mothers; (b) before starting school, when the child is part of an extended family, some of whom may be carriers of the virus, and (c) in early adult life, after the onset of sexual activity. Some infections may be transmitted by multiple use of unsterile needles or instruments, and transfusion of unscreened blood.

The risk that $\mathrm{HBsAg}$ positive mothers will infect their babies varies from country to country and is best correlated with the proportion of women of child bearing age who are $\mathrm{HBeAg}$ positive. Table II shows some illustrative data. Differences in the prevalence of $\mathrm{HBeAg}$ among carrier mothers have important practical implications, as immunisation of babies born to $\mathrm{HBeAg}$ positive mothers is only $50-75 \%$ effective in preventing transmission of $\mathrm{HBV}$, whereas it is $95-100 \%$ effective in preventing infection of children born to $\mathrm{HBeAg}$ negative carrier mothers. ${ }^{30} 32$

While the modes of transmission of $\mathrm{HBV}$ are similar throughout the region, there are considerable variations in the importance of perinatal and household transmission, and transmission by inoculation of blood, secretions or sexual intercourse from country to country. In hyperendemic areas, most infections are acquired early in life, either from the child's mother or some other person in the extended household. By contrast, in low prevalence groups, most infections are acquired in early adult life, through experimentation with intravenous drugs and unprotected sexual intercourse.

One of the most controversial issues is the risk of transmission of infection in schools that contain children from populations with both low and high rates of infection. The issue is difficult because of its implications for public health policy and the opportunities for stigmatisation of certain groups. It is further complicated by contradictory data, which show that rates of transmission in the school setting vary from place to place, perhaps depending on the degree of contact of the children, the nature of their shared activities, and the proportion who are $\mathrm{HBeAg}$ positive. While there is evidence for transmission from Maori to non-Maori children in some parts of New Zealand ${ }^{33}$ and from aboriginal to non-aboriginal children in parts of the Northern Territory of Australia, ${ }^{34}$ there is little evidence of spread between Melanesian and Indian children in Fiji or between children of Asian or Mediterranean background and their Anglo-Saxon schoolmates in urban areas of Australia. ${ }^{35}$ 
TABLE III Impact of universal childhood immunisation programmes: carriage rate in preschool and early school aged children before and after the programme

\begin{tabular}{lccclc}
\hline Country & Year & Percentage & Year & Percentage & Reference \\
\hline Nauru & 1983 & $19 \cdot 7$ & 1990 & 0.9 & 5 \\
Indonesia & 1987 & $6 \cdot 2$ & 1991 & $1 \cdot 4$ & 38 \\
Taiwan & 1984 & $10 \cdot 6$ & 1989 & $1 \cdot 7$ & 39 \\
Thailand & 1988 & $4 \cdot 2$ & 1991 & $1 \cdot 3$ & 40 \\
South China & 1990 & 18.3 & 1994 & $1 \cdot 5$ & 29 \\
\hline
\end{tabular}

Note: these data are not strictly comparable, as the 1983 figures for Nauru relate to children aged 10-19 years, while the others are for children of preschool age.

\section{Impact of vaccination and other policies}

Over the past 20 years, several policy initiatives have occurred in the region, each of which has had an impact on the epidemiology of hepatitis $B$ infection. The first of these was the introduction of screening tests for HBsAg into blood transfusion services, which occurred in highly industrialised countries in the early 1970 s and has been subsequently introduced into many other countries. There is good evidence that, in low prevalence countries at least, this has resulted in a dramatic reduction in the incidence of post-transfusion hepatitis $B$.

Secondly, recognition of the importance of inadvertent inoculation with infected blood, through careless laboratory practice and reuse of needles for injections (both in hospitals and for recreational drug use), has led to a number of initiatives that have had an impact on this problem. Better education, introduction of codes of practice, and improved training have reduced the number of laboratory acquired infections in developed countries, as has introduction of disposable needles and syringes into hospital practice and needle exchange programmes for intravenous drug users. While these initiatives are important, their overall public health impact has been dwarfed by the impact of immunisation programmes.

Hepatitis B vaccines were licensed in the early 1980 s and became available in the region shortly afterwards. Because the vaccines were initially quite expensive (in excess of $\$ 100$ for three adult doses), immunisation was used selectively, being targeted at those who could afford to pay, rather than at those who would provide greatest benefit to the community.

Through the initiatives of a number of countries and the catalytic role of the Western Pacific Regional Office of WHO (through the WPRO Task Force on Hepatitis B) and the International Task Force on Hepatitis B Immunisation, control of hepatitis $\mathbf{B}$ has become a high priority in the region. ${ }^{36}$ Over the past decade, new facilities for the production of hepatitis $B$ vaccine have been established in the Republic of Korea and China to supplement supplies available from manufacturers in Europe and the USA. Increased supplies of vaccine, the impact of competition, subsidies, and other forms of government support have combined to reduce the price of vaccines to a few dollars per paediatric dose, so that many countries are now able to incorporate hepatitis $B$ vaccine into their routine childhood immunisation programmes.

Wide variations in strategy exist. To date, low prevalence countries have largely adopted selective immunisation policies; some, such as Japan, have focused mainly on prevention of transmission from $\mathrm{HBeAg}$ positive carrier mothers, through the use of hepatitis $B$ hyperimmune globulin (HBIg) and hepatitis B vaccine $^{23}$; others, such as Australia, have extended this to $\mathrm{HBeAg}$ negative carrier mothers. To date, New Zealand is the only low prevalence country in the region to have adopted universal childhood immunisation as the preferred approach to preventing perinatal transmission. ${ }^{37}$ Australian authorities are considering making such a change.

The region's first universal childhood immunisation programme was initiated by the Republic of Nauru in $1983 .{ }^{7}$ Since that time, national programmes have been introduced in many countries, with varying degrees of success. While optimal results are obtained when the first dose of vaccine is delivered shortly after birth (and babies born to $\mathrm{HBeAg}$ positive mothers also receive a dose of $\mathrm{HBIg}$ ), this is only possible where babies are born in hospital or the health system enables a vaccinator to make contact with babies born outside hospital shortly after delivery.

The impact of childhood immunisation programmes on perinatal transmission of hepatitis $B$ is a marker of the quality of health care delivery in the country. To date, the most successful programmes have been in Nauru, American Samoa, Taiwan, Japan, and New Zealand, where, despite vastly different health systems, mechanisms exist for contacting all newborn babies at, or shortly after, birth.

Some countries have adopted different mechanisms for distributing hepatitis $\mathrm{B}$ vaccine, preferring to integrate it with the delivery of diphtheria, pertussis and tetanus (DPT) vaccine, thus avoiding the necessity of introducing an additional contact with the baby in the first few days of life. This strategy is likely to be quite effective in countries in which carrier mothers have a low prevalence of $\mathrm{HBeAg}$, but far less valuable in countries where the prevalence of $\mathrm{HBeAg}$ among women of childbearing age is high.

Immunisation programmes have been in place in some countries for a sufficient period to assess their impact. Although the figures vary from country to country, it is fair to say that, in every country in which universal immunisation has been introduced early in life, there has been a considerable reduction in the carrier rate among children (see Table III) and, in some countries, a decline in the rate of infection among older siblings has been noted.

\section{Burden for the next 20 years}

A number of studies conducted in the Asian Pacific region have shown that children who become chronic carriers of $\mathrm{HBsAg}$, as a result of infections acquired early in life, have a greatly increased risk of dying of cirrhosis, chronic active hepatitis or hepatocellular carcinoma. The now classic study by Beasley and his colleagues among middle aged men in Taiwan ${ }^{4}$ showed that carriers of HBsAg had more than 200 times the risk of developing primary liver 
cancer than HBsAg negative controls, matched in other ways. Similar data associating high rates of carriage of $\mathrm{HBsAg}$ with an increased risk of developing severe sequelae have been generated in other countries in the region. 56

Given that, between 1950 and 1990, the average life expectancy in South East Asia increased by $15-25$ years $^{41}$ (due to a major decline in infant mortality and a halving of deaths due to all causes in early adult life), it is reasonable to expect that the burden of chronic hepatitis B infection will continue to increase for three or four decades, as an increasing proportion of adults survive into their $50 \mathrm{~s}$ and $60 \mathrm{~s}$.

\section{The role of precore mutants of $\mathrm{HBV}$ and} coinfection with other agents

The discovery of precore mutants of $\mathrm{HBV}^{42}$ has caused many groups to speculate that virological factors may be important in determining the severity or outcome of infection. While early studies in Japan ${ }^{43} 44$ suggested an association between precore mutants and fulminant hepatitis $\mathrm{B}$, recent studies in Taiwan (and elsewhere) have failed to confirm this association. ${ }^{45} 46$ The clinical and epidemiological significance of mutants of $\mathrm{HBV}$ remains to be defined.

Although it is generally believed that coinfection with hepatitis $\mathrm{C}$ virus ( $\mathrm{HCV}$ ) or hepatitis $\mathrm{D}$ virus (HDV), or both, may result in more severe sequelae than infection with $\mathrm{HBV}$ alone, this is not invariably the case. While a great deal is known about the epidemiology of $\mathrm{HBV}$ in the region, less is known about patterns of infection with HCV and HDV.

HDV seems to be comparatively uncommon in the region, although pockets of high prevalence have been reported among groups of intravenous drug users in Australia and Malaysia and some relatively isolated Pacific island groups, such as Nauru, Niue, Palau, and Western Samoa. ${ }^{47}$ In Nauru, chronic carriers of HBsAg with evidence of active HDV infection (as indicated by the presence of circulating HDV RNA) were three times as likely to have biochemical evidence of chronic liver disease than carriers with detectable anti-HDV but no detectable circulating HDV RNA. Few studies have considered the prevalence of $\mathrm{HCV}$ infection in the region.

Infection with the human immunodeficiency virus (HIV) is an emerging problem in the region, which influences the pattern of chronic hepatitis B infection in two ways. Firstly, the profound immunodeficiency associated with later stages of the disease may complicate interpretation of hepatitis B (and other) serology; secondly, as the mean incubation period of AIDS (10 years) is significantly shorter than the incubation period of cirrhosis or hepatocellular carcinoma (30-40 years), HBsAg carriers who are coinfected with HIV will probably die of AIDS before developing complications of their chronic HBV infection.

Prospects for eradication or control

While it is theoretically possible that hepatitis
B infection could be eradicated by universal childhood immunisation, there are several biological and practical issues that make this extremely difficult, suggesting that, for the foreseeable future, control may be a more realisable goal.

The barriers to successful eradication programmes are severalfold. Firstly, a small proportion of infections occur in utero (from carrier mothers) and cannot be prevented by active or passive immunisation at birth, or both. Secondly, both combined passive/active immunisation and active immunisation fail to prevent some transmission between the most infectious (HBeAg positive) mothers and their newborn babies, irrespective of the doses and schedules used. In general, active/passive immunisation can be expected to reduce transmission from $\mathrm{HBeAg}$ positive carrier mothers by more than $90 \%,{ }^{48}$ compared with a reduction of $70-80 \%$ with high titre $\mathrm{HBIg}^{49} 50$ alone. Thirdly, programmes that rely upon interventions shortly after birth, or within the first days of life, followed by additional injections at defined intervals, are difficult to implement and tend to suffer from a significant drop out rate. Programmes that are highly effective when undertaken as pilot projects with well trained and highly motivated staff in urban areas are often less successful when transferred to rural areas, where the local staff have little training and support, where the population is remote from organised health services, and where contact may become difficult because of heavy rain or conflicting parental priorities. Under these circumstances, health officials are likely to select programmes that are easiest to deliver and will do the most good, with the least disruption of existing programmes.

A good example of this form of thinking exists in Indonesia, where, despite the fact that a model immunisation programme has shown that significantly lower carrier rates $(1.3 \%)$ are obtained when the first dose of vaccine is delivered in the home within 48 hours of delivery than when it is given some time later (3\%), ${ }^{38}$ the government has elected to expand coverage by giving the first dose of vaccine at the same time as the first dose of DPT. While recognising the benefits of the first approach, health planners have opted for the second to conserve resources, accepting a lower efficacy rate and a more gradual control of the disease.

The addition of hepatitis $B$ vaccine to national childhood immunisation programmes requires a minimum of three additional injections in the first year of life, which some health care workers fear may lead to lower completion rates. To allay the concerns of parents and public health workers, most of the major vaccine companies are developing and testing quadrivalent and pentavalent vaccines capable of protecting against diphtheria, pertussis, tetanus, hepatitis $\mathrm{B}$, and polio or haemophilus influenzae $b$ in a course of three injections. If these vaccines can be supplied at acceptable cost, they will probably facilitate coverage and result in a considerable reduction in hepatitis $B$ infection in infants and young children. 
The author gratefully acknowledges Jannett Belfield's assistance in searching and collating the recent literature and Brenda Coffman for preparation of the manuscript.

1 Blumberg BS, Alter HJ, Visnich S. A 'new' antigen in leukaemia sera. $\mathscr{f} A M A 1965 ; 191: 541$.

2 Beasley RP, Trepo C, Stevens CE, et al. The e antigen and vertical transmission of hepatitis B surface antigen. $A m \mathcal{F}$ Epidemiol 1977; 105: 94-8.

3 Stevens CE, Taylor PE, Tong MJ, et al. Prevention of perinatal hepatitis B virus infection with hepatitis B immune globulin and hepatitis B vaccine. In: Zuckerman AJ, ed. Viral hepatitis and liver disease. New York: Alan R Liss, 1988: 982-8.

4 Beasley RP, Lin CC, Hwang LY, et al. Hepatocellular carcinoma and hepatitis B virus: a prospective study of 22707 men in Taiwan. Lancet 1981; ii: 1129-33.

5 Obata $\mathrm{H}$, Hayashi N, Motoike Y. A prospective study of development of hepatocellular carcinoma from liver cirrhosis with persistent hepatitis B virus infection. Int $\mathfrak{f}$ rhosis with persistent

6 Xu Z-Y, Xi L-F, Fu T-Y, Zhou D-K. Cost-benefit and decision analysis of hepatitis B immunisation. Shanghai $\mathcal{f}$ Prevent Med 1989; 1: 24-7.

7 Speed BR, Dimitrakakis M, Thoma K, Gust ID. Control of HBV and HDV in an isolated Pacific island: I. Pattern of infection. F Med Virol 1989; 29: 13-9.

8 Gust ID. Global perspective of viral hepatitis and liver disease: the Western Pacific. In: Nishioka $\mathrm{K}$, et al, eds. Viral hepatitis and liver disease. Tokyo: Springer-Verlag, 1994: 390-3.

9 Sung JL and the Asian Regional Study Group. Hepatitis B virus eradication strategy for Asia. Vaccine 1990;8 (suppl): S95-9.

10 Domingo E, Lansang MA, Ramirez B, et al. Viral hepatitis in the Philippines: a perspective. In: Nishioka K, et al, eds. Viral hepatitis and liver disease. Tokyo: Springer-Verlag, 1994: 400-2

11 Liaw Y-F. Viral hepatitis in Taiwan: status in the 1990s. In: Nishioka $\mathrm{K}$, et al, eds. Viral hepatitis and liver disease. Tokyo: Springer-Verlag, 1994: 419-21.

12 Sulaiman HA. Hepatitis in Indonesia. In: Nishioka K, et al, eds. Viral hepatitis and liver disease. Tokyo: SpringerVerlag, 1994: 394-6.

13 Thompson S, Ruff T. Hepatitis B vaccination: what are the current international recommendations? Clin Immunother 1995; 3: 15-26.

14 Suzuki H. Viral hepatitis in Japan. In: Nishioka K, et al, eds. Viral hepatitis and liver disease. Tokyo: Springer-Verlag, 1994: 426-8

15 Tandon BN, Acharya SK, Dasarathy S, et al. Viral hepatitis in India. In: Nishioka $\mathrm{K}$, et al, eds. Viral hepatitis and liver disease. Tokyo: Springer-Verlag, 1994: 397-9.

16 Tao Q-M, et al. Epidemiology of hepatitis B and C in China. In: Nishioka $\mathrm{K}$, et al, eds. Viral hepatitis and liver disease. Tokyo: Springer-Verlag, 1994: 412-5.

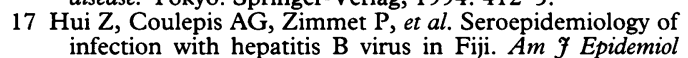
1982; 116: 608-16.

18 Milne A, Allwood GR, Moyes CD, et al. Prevalence of hepatitis B infections in a multiracial New Zealand comhepatitis B infections in a multiracial
munity. NZ Med $\mathcal{7} 1985 ; 98: 529-32$.

19 Wan X, Currie B, Miller N, Mathews JD. Acute hepatitis B infection in aboriginal Australians. Aust $\mathcal{F}$ Publ Health 1993; 17: 331-3.

20 Gust ID. Control of hepatitis B in Australia: the case for alternative strategies. Med f Aust 1992; 156: 819-21.

21 Gust ID, Dimitrakakis M, Zimmet P. Studies on hepatitis B surface antigen and antibody in Nauru. I. Distribution among Nauruans. Am $\mathcal{f}$ Trop Med Hyg 1978; 27: among

22 Tsen YJ, Chang MH, Hsu HY, et al. Seroprevalence of hepatitis B virus infections in children in Tapei, 1989: five years after a mass hepatitis B vaccination programme. y Med Virol 1991; 34: 96-9.

23 Shiraki K. Vertical transmission of hepatitis B virus and its prevention in Japan. In: Nishioka $\mathrm{K}$, et al, eds. Viral hepatitis and liver disease. Tokyo: Springer-Verlag, 1994: $530-2$

24 Lucas CR, Milne A, Hopkirk N. Kawerau revisited: hepatitis A and B seroprevalence in 1984 and 1993. NZ Med $\mathcal{F}$ 1994; 197: 206-8.

25 Speed BR. Republic of Nauru: report on hepatitis B vaccination programme June 1983 to May 1990. Fairfield Hospital, June 1993.

26 Evaluation of the long-term efficacy of hepatitis B vaccination programme in the prevention of chronic carriage of hepatitis B virus. Epidemiological News Bulletin, Singapore 1994; 20: 7-10.

27 Gust ID, Dimitrakakis M, Zimmet P. Studies on hepatitis B surface antigen and antibody in Nauru. II. Distribution in Gilbert and Ellice (Tuvalu) islanders. Am F Trop Med Hyg 1978; 27: 1206-9

28 Gust ID, Lehmann NI, Dimitrakakis M, Zimmet P. A seroepidemiologic study of hepatitis A and B infection in an isolated Pacific population. I Infect Dis 1979; 139: 559-63.

$29 \mathrm{Xu} \mathrm{Z-Y.} \mathrm{Epidemiology} \mathrm{of} \mathrm{hepatitis} \mathrm{B.} \mathrm{In:} \mathrm{Wen} \mathrm{Y-M,} \mathrm{et} \mathrm{al,}$ eds. Viral hepatitis in China: problems and control strategies. Monogr Virol. Basel: Karger, 1992; 19: 99-110.

30 Hwang L-Y, Lee C-Y, Beasley RP. Five-year follow-up of HBV vaccination with plasma-derived vaccine in neonates: evaluation of immunogenicity and efficacy against perinatal transmission. In: Hollinger FB, Lemon
SM, Margolis HS, eds. Viral hepatitis and liver disease. Baltimore: Williams and Wilkins, 1991: 759-61.

31 Gilbert GL. Prevention of vertical transmission of hepatitis B. Med f Aust 1984; 141: 213-6.

32 André FE, Zuckerman AJ. Review: protective efficacy of hepatitis B vaccines in neonates. $\mathcal{f}$ Med Virol 1994; 44: 144-51.

33 Milne A. Viral hepatitis in the Eastern Bay of Plenty. NZ Med F 1980; 92: 85-7.

34 Campbell DH, Sargent JW, Plant AJ. The prevalence of markers of infection with hepatitis $B$ virus in a mixed-race Australian community. Med f Aust 1989; 150: 489-92.

35 Burgess MA, McIntosh EDG, Allars HM, Kenrick KG. Hepatitis B in urban Australian schoolchildren: no evidence of horizontal transmission between high-risk and low-risk groups. Med f A ust 1993; 159: 315-9.

36 Muraskin W. The war against hepatitis $B$. A history of the international task force for hepatitis $B$ immunisation. international task force for hepatitis $B$ immunisation. $1-248$.

37 Milne A. Hepatitis B vaccination in New Zealand. Aust $\mathcal{f}$ Publ Health 1993; 17: 398 .

38 Ruff TA, Gertig DM, Otto BF, et al. Lombok hepatitis B model immunisation project: toward universal infant hepatitis B immunisation in Indonesia. F Infect Dis 1995; 171: 290-6.

39 Wong WCW, Tsang KK. A mass hepatitis B vaccination programme in Taiwan: its preparation, results and reasons
for uncompleted vaccinations. Vaccine 1994; 12: 229-34.

40 Chainuvati T. Perspective of viral hepatitis in Thailand. In: Nishioka $\mathrm{K}$, et al, eds. Viral hepatitis and liver disease. Tokyo: Springer-Verlag, 1994: 403-5.

41 World Bank. World Development Report 1993. New York: Oxford University Press, 23.

42 Carman WF, Jacyna MR, Hadziyannis $S$, et al. Mutation preventing formation of hepatitis $B$ e antigen in patients with chronic hepatitis B infection. Lancet 1989; ii: 588-91.

43 Kosaka Y, Takase K, Kojima M, et al. Fulminant hepatitis $B$ : induction by hepatitis $B$ virus mutants defective in the precore region and incapable of encoding e antigen. Gastroenterology 1991; 100: 1087-94.

44 Omata M, Ehata T, Yokosuka O, et al. Mutations in the precore region of hepatitis B virus DNA in patients with fulminant and severe hepatitis. $N$ Engl f Med 1991; 324: 1699-704.

45 Hsu H-Y, Chang M-H, Lee C-Y, et al. Precore mutant of hepatitis B virus in childhood fulminant hepatitis B: an infrequent association. $\mathcal{F}$ Infect Dis 1995; 171: 776-81.

46 Laskus T, Persing DH, Nowicki MJ, et al. Nucleotide sequence analysis of the precore region in patients with fulminant hepatitis $B$ in the United States. Gastroenterology 1993; 105: 1173-8.

47 Dimitrakakis M, Gust ID. HDV Infection in the Western Pacific Region. In: Gerin JL, Purcell RH, Rizzetto M, eds. The hepatitis delta virus. New York: Wiley-Liss, 1991: 89-96.

48 Beasley RP, Hwang LY, Lee GC, et al. Prevention of perinatally transmitted hepatitis $B$ virus infections with hepatitis $B$ immunoglobulin and hepatitis $B$ vaccine. Lancet 1983; ii: 1099.

49 Beasley RP, Hwang LY, Lin CC, et al. Hepatitis B immunoglobulin (HBIG) efficacy in the interruption of perinatal transmission of hepatitis B virus carrier state. Lancet 1981; ii: 388-93.

50 Beasley RP, Hwang LY, Stevens CE, et al. Efficacy of hepatitis B immunoglobulin (HBIG) for prevention of perinatal transmission of the HBV carrier state: final report of a randomised, double-blind placebo-controlled trial. Hepatology 1983; 3: 135-41.

\section{Discussion}

Goudeau: Can you give us your impression of the self sufficiency of the area in terms of vaccine production?

Gust: I think that almost any company in the world that is currently producing hepatitis B vaccine has the potential to produce the total requirements of the world simply by scaling up their production facility. In our region, a significant amount of plasma derived vaccine is being produced. I don't think the problem is so much one of inadequate supply but is rather a question of national priorities. Part of the problem is that hepatitis B vaccine is inherently more expensive than any other vaccine that has ever been included in an EPI. The other vaccines were developed using very simple technology and were licensed before there were proper regulatory agencies. Hepatitis B vaccines, on the other hand, now require very sophisticated technology to develop and have to go through a very complex regulatory 
process. Countries are now being forced to recognise that they have to start allocating resources and considering their priorities whether to spend their money on arms or on vaccines, for example. Combination vaccines are not an answer, but part of the same problem.

$A h n$ : Can you give an explanation for the big differences in the HBsAg positivity rates in the Nauru villages?

Gust: There seems to be clustering of infections surrounding an $\mathrm{HBeAg}$ positive mother because it is likely that her children also will be $\mathrm{HBeAg}$ positive and that they will transmit the infection to other siblings or other children within the household. These early infections are likely to result in chronic carrier status.

$A h n$ : In Korea, I have observed certain area differences in the HBsAg positivity rates. For example, the coastal area generally has higher carrier rates than the mountainous area. I don't know why.

Zuckerman: How is hepatitis B transmitted in the school setting?

Gust: We don't really know the answer to this. Many studies have been done, with widely differing results. In Australia and New Zealand, there are four major studies. Two of these show good evidence of transmission, one amongst Maoris and non-Maori school children in New Zealand and one in the Northern Territory amongst Aboriginal and nonAboriginal school children. In both these settings, the children run around bare footed. They often have scratches and it is possible that when they are playing and fighting together, transmission occurs through serous exudates on the skin. Two other studies that have been conducted in cooler urban areas in Australia, in school children of Asian and nonAsian origin, have shown no increase in transmission. Politically, it is an extraordinarily sensitive issue.
Toukan: The decreases in hepatitis B carrier rates since the introduction of prevention programmes are very impressive. I wonder how much vaccination is contributing to this and how much it might be due to changes in socioeconomic status. Do you know of any control studies - that is, repeat surveys of unvaccinated populations after an interval of five or 10 years?

Gust: Most of the studies have been conducted on a national basis, so there is no internal control. One exception is Indonesia, where the vaccination programme was initially confined to the island of Lombok, which has a population of about three million. Parallel studies carried out in villages in other parts of Indonesia, where hepatitis B vaccine was not administered, showed no change in carrier rates. This suggests that the changes seen amongst the immunised population in Lombok are vaccine related.

Torres: Is your approach to hepatitis B control in Aborigines any different to that in the general population in Australia?

Gust: Yes, it is. Australia is one of the only countries in the Western Pacific region that does not yet have a national hepatitis $B$ immunisation programme. That is, there is not yet a Government funded programme to administer vaccine to every newborn baby. For seven or eight years, however, there has been a selective immunisation programme, which provides free vaccine to babies born into Aboriginal families, even if the babies are only one sixteenth Aboriginal. Free vaccine is also provided for babies born to carrier mothers and babies born into families where the carrier rates are higher than among the Anglo-Saxon population. The Australian National Health and Medical Research Council is currently reconsidering the immunisation strategy and is likely soon to promote universal infant immunisation. 